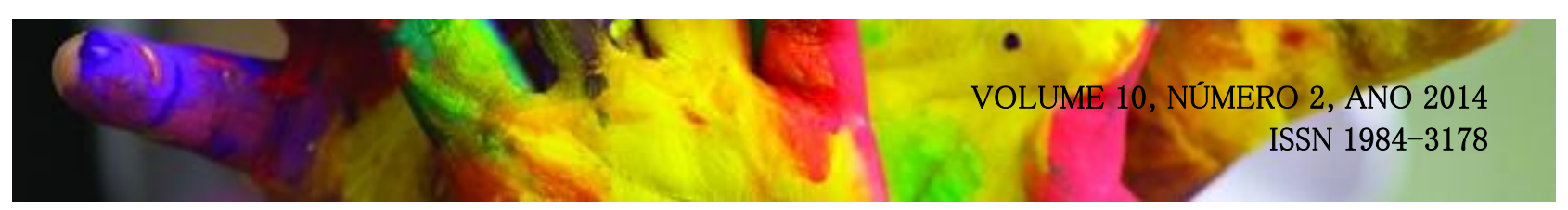

\title{
POLÍTICAS DE EDUCAÇÃO INCLUSIVA: CONSIDERAÇÕES SOBRE A AVALIAÇÃO DA APRENDIZAGEM DE ALUNOS COM DEFICIÊNCIA INTELECTUAL
}

DOI: http://dx.doi.org/10.5965/198431781022014125

\author{
Márcia Denise Pletsch ${ }^{1}$ \\ Mariana Corrêa Pitanga de Oliveira ${ }^{2}$
}

\section{RESUMO}

O presente artigo objetivo apresentar reflexões sobre as políticas de inclusão escolar e a avaliação da aprendizagem de alunos com deficiência intelectual. A investigação integra uma pesquisa, em andamento, vinculada ao Observatório de Deficiência Intelectual - (OBEDUC/CAPES) fundamentada na perspectiva histórico-cultural. Em termos metodológicos foram adotados os referenciais da pesquisa qualitativa com análise de documentos oficiais e dados empíricos coletados em cinco municípios da Baixada Fluminense, Estado do Rio de Janeiro. A partir da análise das informações de campo e seu cotejamento com as diretrizes oficiais e a literatura especializada, verificamos que apesar dos avanços na implementação das políticas de inclusão escolar, as escolas, de maneira geral, não valorizam e/ou não utilizam instrumentos avaliativos que viabilizam o acompanhamento do processo de ensino e aprendizagem de alunos com deficiência intelectual. Igualmente, ficou evidente que os processos avaliativos continuam focando as impossibilidades dos alunos e não as suas possibilidades de aprendizagem e desenvolvimento a partir das intervenções e mediações pedagógicas.

Palavras-chave: Políticas de educação inclusiva; avaliação escolar; deficiência intelectual; processos de ensino e aprendizagem; perspectiva histórico-cultural.

\section{INCLUSIVE EDUCATION POLICIES: \\ SOME CONSIDERATIONS ON THE LEARNING ASSESSMENT OF STUDENTS WITH INTELLECTUAL DISABILITIES}

\begin{abstract}
This article intends to present some reflections on school inclusion policies and the learning

1 Professora Adjunta do Departamento de Educação e Sociedade do Instituto Multidisciplinar e do Programa de PósGraduação em Educação, Contextos Contemporâneos e Demandas Populares (PPGEduc/UFRRJ).

2 Mestranda em Educação do Programa de Pós-Graduação em Educação, Contextos Contemporâneos e Demandas Populares (PPGEduc/UFRRJ) com bolsa da CAPES/OBEDUC.
\end{abstract}




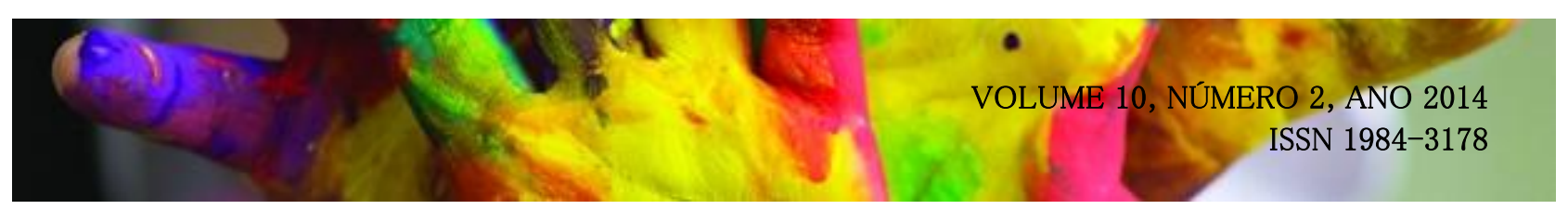

assessment of students with intellectual disabilities. The investigation is part of ongoing research linked to the Observatory of Intellectual Disability (Observatório de Deficiência Intelectual OBEDUC/CAPES) using a historical and cultural perspective. In methodological terms, qualitative research was used, involving the analysis of official documents and empirical data collected in five municipalities in Baixada Fluminense, Rio de Janeiro state. Based on the information collected in the field and its comparison with official directives and specialized literature, we found that despite advances in the implementation of school inclusion policies, schools, generally speaking, did not valorize and/or use assessment instruments which allowed the monitoring of the teaching process or the learning of students with intellectual disabilities. Equally, it was evident that assessment processes continued to focus on the impossibilities of students rather than their possibilities for learning and development through pedagogic interventions and mediations.

Keywords: Inclusive education policies; school assessment; intellectual disabilities; teaching and learning processes; historical and cultural perspective.

\title{
Para iniciar...
}

\begin{abstract}
Os indivíduos possuidores de alguma deficiência assistem ao esgotamento de suas possibilidades de aprendizagem, uma vez que a própria dinâmica educativa solicita resultados que só podem ser atingidos ao apresentarem um suposto padrão considerado normativo. Portanto, inclusão escolar não pode se tratar apenas da colocação de indivíduos historicamente diferenciados e estigmatizados diante de um currículo que apresenta problemas graves de qualidade expressos pelos baixos níveis de aprendizagem que alcançam e altos níveis de evasão e repetência que proporcionam. Para que esse fato se materialize, a escola precisa enfatizar a reflexão e o diálogo, determinados pelo conhecimento, esclarecimento, isto é, por tudo aquilo que a cultura estabeleceu como verdadeiro na luta contra os mitos (MENDES E SILVA, 2014, p. 12).
\end{abstract}

A partir de discussões e investigações realizadas no âmbito do grupo de pesquisa "Observatório de Educação Especial e inclusão escolar: práticas curriculares e processos de ensino e aprendizagem", nossos estudos têm buscado a partir da perspectiva histórico-cultural, embasamento para refletir e analisar os processos de ensino e aprendizagem de alunos que apresentam necessidades educacionais especiais em decorrência de diferentes deficiências, em particular, neste artigo focaremos o caso das pessoas com deficiência intelectual.

Antes de prosseguirmos cabe mencionar que a proposta de inclusão escolar vem se constituindo nas últimas décadas enquanto política prioritária na educação brasileira. O discurso em 


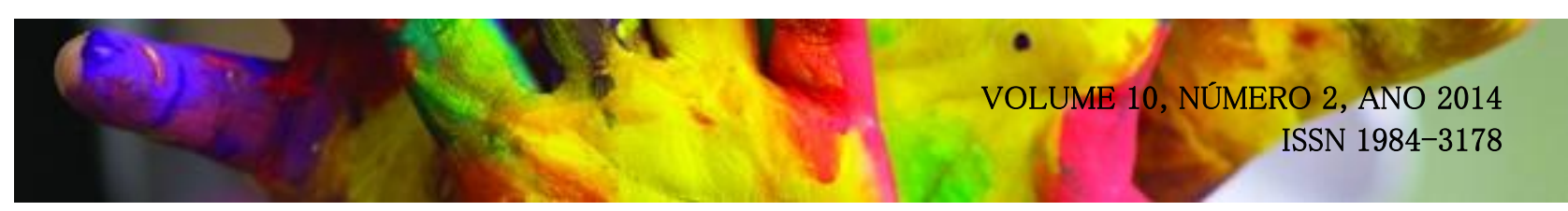

prol da educação para todos se consolidou nos anos de 1990 fortemente influenciado por diretrizes internacionais. Dentre elas, destaca-se a Declaração de Salamanca considerada um marco para a Educação Especial (UNESCO, 1994). Os seus princípios, entre outros documentos, foram incorporados em parte na aprovação da Lei de Diretrizes e Bases da Educação Nacional (LDB, Lei 9.394/96) que dedicou um capítulo a Educação Especial prevendo pela primeira vez a existência de apoio especializado na escola regular (BRASIL, 1996; PLETSCH, 2014a).

Em que pesem os avanços anteriores, no Brasil, os debates sobre a educação inclusiva e suas dimensões políticas intensificaram-se a partir dos anos 2000, especialmente a partir do Governo de Luiz Inácio Lula da Silva (2003/2010). Nesse período diversos documentos aprofundaram as reflexões sobre qual seria a melhor forma de escolarização para o público alvo da Educação Especial, fundamentados nas políticas de educação inclusiva, entendida aqui como um processo no qual a escola deve receber condições reais de inserir o aluno levando em consideração suas especificidades no processo de ensino aprendizagem, dando o suporte necessário para que o indivíduo se desenvolva. Assim, entendemos que para além do acesso e permanência é preciso garantir ao sujeito com deficiência a garantia real de sua aprendizagem e seu consequente desenvolvimento.

Ainda em termos legais cabe mencionar as mudanças recentes que tem exigido transformações nas redes de ensino para atender as diretrizes em vigor a partir de 2008 com a Política Nacional de Educação Especial na Perspectiva da Educação Inclusiva (BRASIL, 2008) e as Diretrizes Operacionais do Atendimento Educacional Especializado na Educação Básica, modalidade Educação Especial (BRASIL, 2009). Tais documentos, amplamente analisados por Kassar (2012) e Souza (2013), entre outros aspectos, evidenciam que a inclusão deve se dar em todos os níveis de ensino, desde a educação infantil até o ensino superior. Outra indicação se refere ao suporte educacional especializado que deve ocorrer prioritariamente em salas de recursos multifuncionais por meio das propostas do atendimento educacional especializado (AEE), como complemento e suplemento ao ensino comum e não como espaços substitutivos de escolarização, conforme ocorria/ocorre historicamente em escolas especiais e nas classes especiais (BRASIL, 2008; 2009). Vale esclarecer que o público alvo da Educação Especial nesses documentos é caracterizado como aquelas pessoas que apresentam deficiência mental ou sensorial, alunos com 


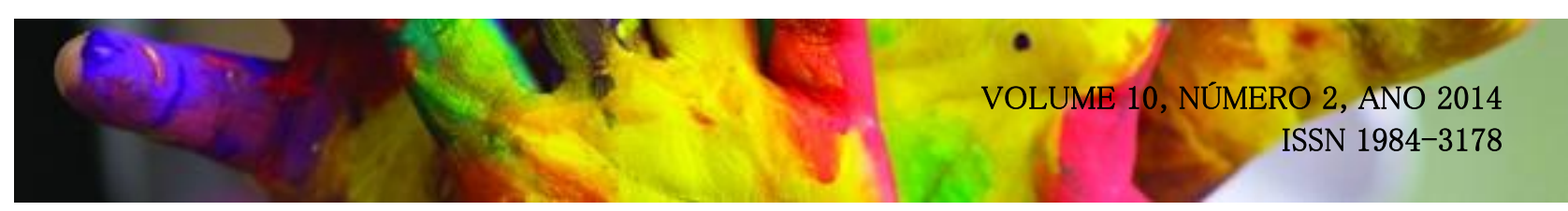

transtornos globais do desenvolvimento e alunos com altas habilidades/superdotação (BRASIL, 2008).

A partir dessas considerações iniciais apresentaremos, neste artigo, considerações sobre a avaliação da aprendizagem dos alunos com deficiência intelectual ${ }^{3}$, com ênfase no que dizem os documentos federais e a decorrente aplicação dessas diretrizes nas práticas escolares contemporâneas. Para tal, propomos um diálogo entre o que dizem os documentos e os dados coletados por meio de pesquisas empíricas realizadas em redes de ensino da Baixada Fluminense, Estado do Rio de Janeiro. Nossa perspectiva metodológica para a coleta dos dados de campo segue os princípios da pesquisa qualitativa usando procedimentos como a observação de práticas pedagógicas e entrevistas semiestruturadas (MIOTO \& LIMA, 2007). Também usamos dados sobre a elaboração conceitual de alunos com deficiência intelectual (LURIA, 1986). A pesquisa integra as ações do projeto "Observatório da Educação - A escolarização de alunos com deficiência intelectual: políticas públicas, processos cognitivos e avaliação da aprendizagem”, desenvolvido em rede pelos Programas de Pós-Graduação em Educação da UFRRJ, UDESC e Univali.

Nosso foco, aqui, é propor reflexões sobre como a avaliação tem sido realizada no contexto escolar e como as instituições educativas tem favorecido e assegurado os processos de ensino e aprendizagem, valorizando não só o produto final do aprendizado escolar (definido em uma nota/conceito), mas também levantando e explorando as possibilidades de desenvolvimento desses sujeitos a partir das intervenções e mediações pedagógicas. Para atingir tais objetivos nossos dados e reflexões serão cotejados com a literatura especializada. Dentre os principais autores destacamos Glat e Pletsch (2011, 2013), Braun (2012), Pletsch (2012, 2014), Valentim (2011), Machado (2013), Valentim \& Oliveira (2013), Machado (2013); Souza (2013), Tartuci (2014) e Mendes e Silva (2014).

Dessa forma, esperamos contribuir com o debate e o enriquecimento teórico-político sobre a avaliação da aprendizagem de sujeitos que apresentam tempos de aquisição do aprendizado

\footnotetext{
${ }^{3}$ O uso do referido termo vem sendo indicado pela Associação Americana de Deficiência Intelectual e Desenvolvimento (AADID). De acordo com a entidade, a deficiência intelectual caracteriza-se por "limitações significativas tanto no funcionamento intelectual como na conduta adaptativa e está expresso nas habilidades práticas, sociais e conceituais, originando-se antes dos dezoito anos de idade" (AADID, 2010, p.31). Para uma definição mais detalhada do conceito ver Pletsch \& Oliveira (2013).
} 


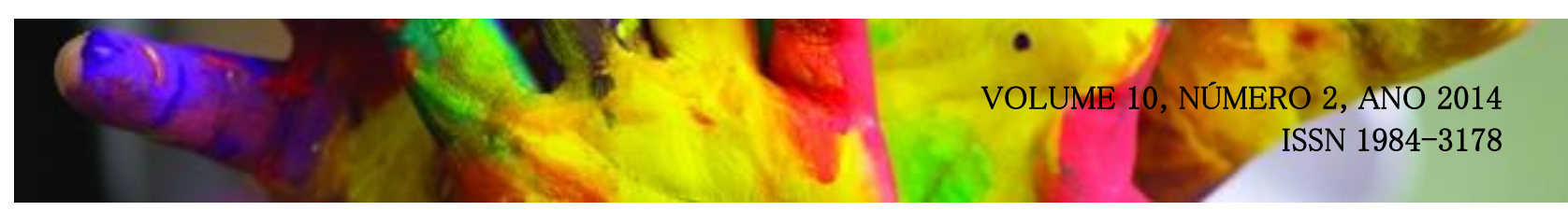

diferenciados do grupo referência ao qual fazem parte, direta ou indiretamente, ressaltando a importância da avaliação dinâmica, assistida e explicativa. Igualmente, pretendemos contribuir com o a produção do conhecimento sobre as concepções em relação ao processo avaliativo de alunos com deficiência intelectual no ensino regular, seus entraves e possibilidades.

\section{Dialogando entre os resultados da pesquisa e a literatura especializada}

Analisando as diretrizes federais no que se refere à avaliação da aprendizagem dos alunos com deficiência intelectual, a partir dos anos 2000, encontramos em 2001 o documento "Diretrizes Nacionais para Educação Especial na Educação Básica” que definiu a avaliação pedagógica dos alunos como "processo permanente de análise das variáveis que interferem no processo de ensino e aprendizagem, para identificar potencialidades e necessidades educacionais dos alunos e as condições da escola para responder a essas necessidades" (BRASIL, 2001, p. 34). Isto é, desde 2001 as diretrizes já indicavam em termos legais indícios sobre como deveria ser encaminhada a avaliação da aprendizagem das pessoas com deficiências.

Nos anos seguintes com as mudanças na estrutura do funcionamento da Educação Especial, sobretudo com a Política atualmente em vigor, tivemos nossas propostas no que diz respeito ao processo de avaliação. Vejamos o que diz a Política Nacional de Educação Especial na Perspectiva da Educação Inclusiva:

A avaliação pedagógica como processo dinâmico considera tanto o conhecimento prévio e o nível atual de desenvolvimento do aluno quanto às possibilidades de aprendizagem futura, configurando uma ação pedagógica processual e formativa que analisa o desempenho do aluno em relação ao seu progresso individual, prevalecendo na avaliação os aspectos qualitativos que indiquem as intervenções pedagógicas do professor. No processo de avaliação, o professor deve criar estratégias considerando que alguns alunos podem demandar ampliação do tempo para a realização dos trabalhos e o uso da língua de sinais, de textos em Braille, de informática ou de tecnologia assistiva como uma prática cotidiana (BRASIL, 2008, p. 11).

Como podemos depreender o documento traz esclarecimentos sobre o processo avaliativo e sobre como o mesmo deve ser realizada pelos professores. Esse é um importante passo para pensarmos o processo de ensino e aprendizagem dos alunos com deficiência intelectual, pois, à 


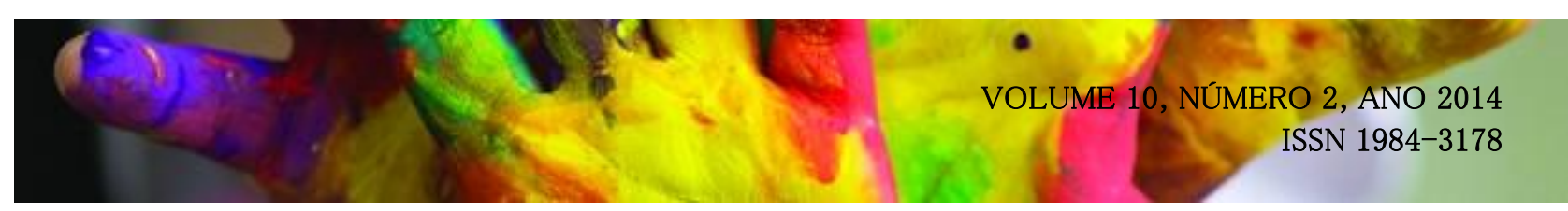

medida que a avaliação é compreendida enquanto prática capaz de mensurar as possibilidades e avanços no aprendizado desse sujeito, também fica claro que a mesma não deve ocorrer como ato nivelador de inteligência e sim como instrumento capaz de acompanhar o desenvolvimento do educando, respeitando os diferentes tempos de aprendizagem. Todavia, essa ainda não é uma realidade na maioria das escolas. Nossos dados de campo mostraram que a avaliação ainda é pouco explicativa sobre as possibilidades do sujeito. Em grande medida, as práticas avaliativas, continuam avaliando as impossibilidades, as quais focam nas características do déficit. Práticas dessa natureza têm sido construídas historicamente na educação dessas pessoas (PLETSCH, 2014a).

Os dados também mostraram que o laudo continua, em grande medida, sendo usado como referência para garantir não apenas os direitos educacionais desses sujeitos como a matrícula nas salas de recursos multinacionais que integram o atendimento educacional especializado (AEE), como também, é usado como base para as práticas pedagógicas. Durante as entrevistas foi comum ouvirmos relatos como "para esses que não são laudados fica complicado realizar uma prática" (Professora de AEE em entrevista no primeiro semestre de 2013). Desconstruir práticas focadas na cultura da impossibilidade é um grande desafio. Nessa direção, a Diretoria de Políticas de Educação Especial disponibilizou, em janeiro de 2014, uma nota técnica orientando as redes de ensino sobre os procedimentos a serem adotados na avaliação e no encaminhamento de alunos com deficiências, transtornos globais do desenvolvimento a altas habilidades/superdotação para o AEE. Segundo ela, a avaliação do aluno deve ocorrer por meio do plano de AEE, a ser elaborado a partir de um estudo de caso. Já, o diagnóstico clínico deve ser usado como documento complementar ao estudo de caso (BRASIL, 2014). Esperamos que essa nota contribua para transformar a cultura do uso do laudo ainda tão presente em nossas instituições de ensino para avaliar as pessoas com deficiência intelectual de forma tão negativa e determinante para as suas trajetórias escolares e de vida.

As práticas avaliativas negativas presentes na avaliação da aprendizagem de alunos com deficiência intelectual são comuns à educação brasileira que tradicionalmente, tem optado por realizar avaliações de maneira descontextualizada e limitadora, na qual a verificação da aprendizagem é preterida, uma vez que o dado é coletado de maneira acrítica e se encerra nele mesmo. Isto é, após a informação reproduzida na prova e/ou trabalho o assunto é encerrado. Em nosso entendimento, a avaliação deve ir além do ato de verificar e classificar, pois um ensino 


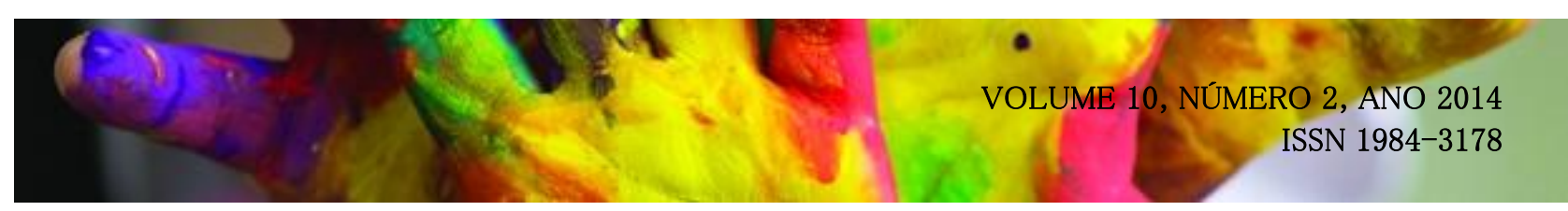

baseado apenas no que já foi produzido, em detrimento às ações que poderiam ser realizadas pela escola, não favorecerá o processo de ensino e aprendizagem dos sujeitos com ou sem deficiência. Na perspectiva histórico-cultural de Vigotski a avaliação é vista como um processo contínuo e não como um fim em si.

Nessa perspectiva Valentim \& Oliveira (2011) nos trazem reflexões sobre o que avaliar; como avaliar; para que (ou quem) avaliar? Esses são questionamentos que deveriam perpassar todo o processo educativo, de forma que "a ação de avaliar possa servir para perceber o movimento e apontar caminhos na prática pedagógica, não classificar, rotular e estigmatizar” (p. 27). As palavras das autoras são pertinentes e revelam a importância do processo avaliativo e sua flexibilização frente às especificidades de alunos com deficiência intelectual, já que quando estas não são respeitadas o estigma de "pior aluno" prejudica não só o seu desenvolvimento, como também corrobora a (falsa) ideia de que o baixo desempenho escolar é inerente à deficiência.

No tocante a opinião das professoras sobre a aprendizagem dos alunos com deficiência intelectual a inserção no contexto escolar apenas como possibilidade do desenvolvimento social ainda é muito presente. Em outros casos, os depoimentos sinalizaram para a possibilidade de aprendizagens focadas no uso de recursos concretos. Dessa forma não favorecendo o desenvolvimento dos processos psicológicos superiores a partir de intervenções e mediações que possibilitem a elaboração conceitual necessária para aprendizagem escolar. Os dados referentes à avaliação sobre a elaboração conceitual dos alunos participantes da pesquisa evidenciaram, na maioria dos casos, entre outros aspectos, a desfasagem entre a idade dos sujeitos e suas respostas. As respostas foram infantilizadas e em alguns casos descontextualizados com os exercícios que estavam sendo propostos.

Segundo pesquisas de Schutz (2013) e Valentim (2011) a maioria dos docentes, e acrescentamos aqui os familiares, esperam respostas imediatas dos educandos. Com isso, tendem a não admitir tempos de aprendizagem (ritmos) mais lentos, o que de acordo com elas ocorre com frequência no desenvolvimento da atividade pelos estudantes com deficiência intelectual. Isso se revela em falas como "ele é muito devagar" e/ou "eu não consigo atingir ele, o ritmo é muito lento". Embora, por vezes as educadoras também afirmem que, de certa maneira, as atividades oferecidas 


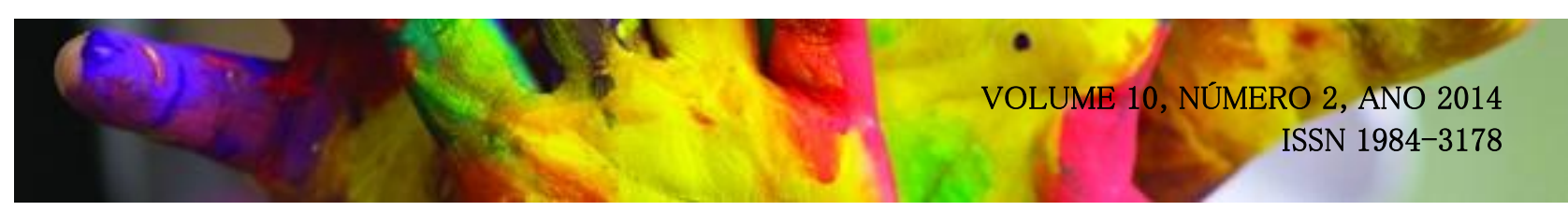

são chatas, repetitivas e pouco significantes para o desenvolvimento cognitivo dos mesmos. Assim, podemos depreender que a complexidade da prática docente expõe não só as contradições do ambiente escolar, bem como a discrepância entre as propostas da política educacional e prática pedagógica desenvolvida nas escolas. Nesse sentido, defendemos que:

\begin{abstract}
A formação docente no contexto das políticas de inclusão escolar deve ser fundamentada em conhecimentos que façam a necessária articulação entre o "micro" e o "macro" contexto social, político e econômico. Mas, sobretudo, em conhecimentos sobre os processos de ensino e aprendizagem a serem afetados para garantir aos alunos um desenvolvimento mais autônomo e cidadão. Igualmente, entendemos ainda, que não basta implementar políticas de inclusão sem oferecer aos docentes reais condições para atender seus alunos com deficiências, transtornos globais do desenvolvimento e altas habilidades (PLETSCH, 2014, p. 127).
\end{abstract}

Ainda no que diz respeito à formação de professores, nos deparamos com o documento "Formação Continuada a Distância de Professores para o Atendimento Educacional Especializado Deficiência Mental”, projeto pertencente ao programa Educação Inclusiva: direito à diversidade, disponibilizado em 2007 e organizado pelo Ministério da Educação (MEC), em parceria com a Secretaria de Educação Especial - incorporada em 2011 pela Secretaria de Educação Continuada, Alfabetização e Diversidade (SECADI). De acordo com a apresentação do documento, este foi organizado visando fundamentar os professores na reorientação das suas práticas, principalmente no Atendimento Educacional Especializado (BRASIL, 2007). A relevância desse material para essa pesquisa é que o mesmo apresenta um capítulo destinado à avaliação da aprendizagem de crianças com deficiência intelectual, no qual exemplifica atividades desenvolvidas em sala de aula, fundamentando-as teoricamente.

No entanto, apesar da relevância do material para o reconhecimento e compreensão das estratégias de leitura e escrita utilizadas pelo aluno com deficiência intelectual, o documento não aborda consideravelmente como deve ocorrer o processo avaliativo de modo que se respeitem as especificidades dos sujeitos que possuem essa deficiência. A este respeito, ressaltamos que o ato de avaliar se constitui em uma das principais funções da prática pedagógica do professor, dito isso, torna-se fundamental compreendermos as diferentes concepções de avaliação presentes no processo avaliativo, ao invés de transformar uma única interpretação dessa prática pedagógica como definitiva.

Embasadas nas proposições de Vigotski, pesquisas recentes (VALENTIM, 2011; BRAUN, 


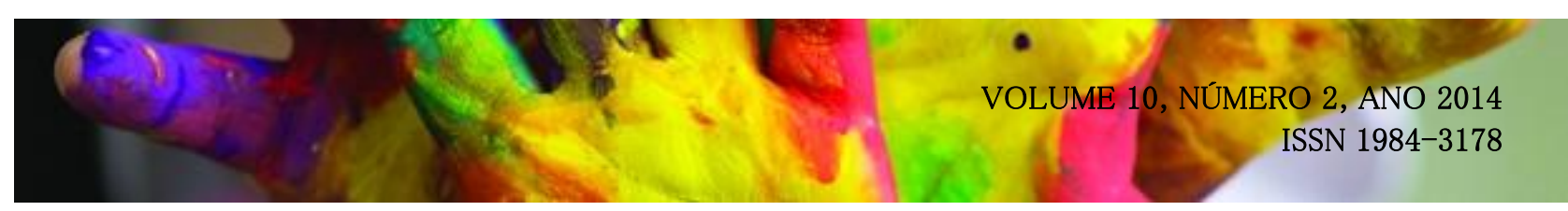

2012; MACHADO, 2013; VALENTIM \& OLIVEIRA, 2013; PLETSCH \& OLIVEIRA, 2013; PLETSCH \& GLAT, 2013; TARTUCI, 2014) defendem a avaliação assistida/dinâmica/mediada e explicativa $^{4}$ como fundamental para que o desenvolvimento potencial dos alunos seja revelado. Trata-se de compreender a avaliação como um processo intencional, capaz de compreender como o sujeito aprende e não só o que ela já aprendeu. Além disso, a prática desmistifica a ideia de que o suporte pedagógico não deve ocorrer durante a fase da avaliação, pois, concordamos com Valentim (2011) ao afirmar que a função da avaliação é "colaborar no desvelamento do potencial dos alunos com deficiência intelectual, para que ocorra uma sistematização de práticas favorecedoras de aprendizagem" (p.33).

Dessa maneira, a avaliação deve ser compreendida como um processo, que possui etapas diferentes e necessárias. É importante destacar, que não estamos aqui negando a importância das avaliações escritas formais (provas/testes) e sim salientando que estes não são os únicos instrumentos existentes, tampouco imprescindíveis no decorrer do processo avaliativo. De acordo com Pletsch \& Glat (2013), existem inúmeras maneiras para realizar processos avaliativos. As referidas autoras mostram, por exemplo, como o portfólio pode ser um importante instrumento para organizar os registros das atividades realizadas pelos alunos por um período determinado. Os registros em portfólio podem ocorrer por meio de fotografias, desenhos, material produzido pelo sujeito em atividades de sala de aula e até mesmo por meio de artesanatos produzidos pelos sujeitos. Tal procedimento, juntamente com outras formas de registro, viabiliza o acompanhamento do processo educacional de cada sujeito.

Nesta perspectiva, compreendemos que as ações de intervenção com sujeitos com deficiência intelectual envolvem a elaboração e a implementação de estratégias em diálogo com o currículo ou a proposta de ensino da instituição em suas diferentes dimensões (planejamento, metodologias, estratégias de ensino, avaliação, tempo e espaço de aprendizagem, entre outros). Essas ações devem ser desenvolvidas de forma coletiva pelos profissionais que atuam na instituição escolar. Aqui cabe lembrar que os ajustes ou flexibilizações necessárias no currículo não podem ser usadas para minimizar ou empobrecer os conteúdos e objetivos a serem atingidos. Por isso é tão

\footnotetext{
${ }^{4}$ Utilizaremos nesse trabalho os termos "avaliação assistida", avaliação "dinâmica" e/ou avaliação mediada como sinônimos.
} 


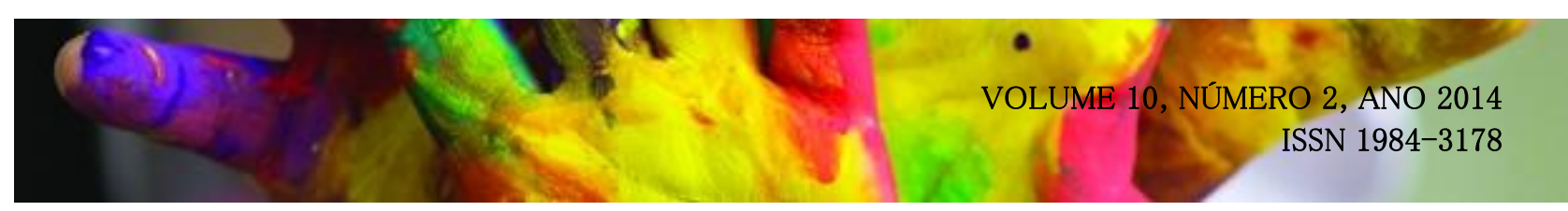

importante e necessário realizar avaliações periódicas, as quais devem fornecer elementos para eventuais revisões a serem realizadas nas intervenções e mediações pedagógicas junto ao sujeito, e não, como frequentemente ocorre, para detectar erros e dificuldades da pessoa com deficiência intelectual (PLETSCH \& GLAT, 2013).

Ainda sobre a avaliação enfatizamos que não existem modelos prontos capazes de atender a todas as nossas demandas profissionais na atuação juntamente com pessoas com deficiência intelectual. $\mathrm{O}$ que temos que entender é que existem diferentes parâmetros e possibilidades para avaliar o processo de ensino e aprendizagem desses sujeitos. As formas avaliativas devem ser usadas para auxiliar no planejamento das ações de intervenção e não para rotular e estigmatizar o sujeito, conforme já sinalizamos anteriormente.

Em suma, não pretendemos esgotar o tema. Pelo contrário, abordamos e apresentamos dados de uma pesquisa ainda em andamento. Contudo, acreditamos que os apontamentos e reflexões apresentadas neste artigo, indicam que uma avaliação focada somente em notas, por si só, não tem a capacidade de evidenciar todas as aprendizagens de um aluno. Além disso, os dados em diálogo com a literatura nos indicaram que existem instrumentos avaliativos que viabilizam o acompanhamento do processo de ensino e aprendizagem desses alunos, revelando as possibilidades de desenvolvimento dos sujeitos e as suas especificidades. Esperamos que outras pesquisas com essa temática sejam realizadas, acompanhando o desenrolar desse processo avaliativo no âmbito das escolas, ampliando o debate sobre as práticas de ensino frente às diretrizes presentes nas políticas de educação inclusiva.

Ainda no que tange as análises dessa pesquisa, os dados ilustraram que a preocupação central do ato avaliativo está no produto e não no processo. Isto é, enquanto continuarmos dando ênfase à nota do aluno e ao que ele não sabe fazer, ao invés de buscarmos a partir do que ele já faz sozinho o suporte necessário para atingirmos seu desenvolvimento potencial, com ações e instrumentos adequados de avaliação, prosseguiremos corroborando práticas pedagógicas que não respeitam às especificidades dos alunos com deficiência intelectual. Neste sentido, a epígrafe inicial nos dá pistas sobre as transformações curriculares necessárias para de fato e de direito possibilitarmos práticas que favoreçam o desenvolvimento de todos os sujeitos independentemente de suas condições. 


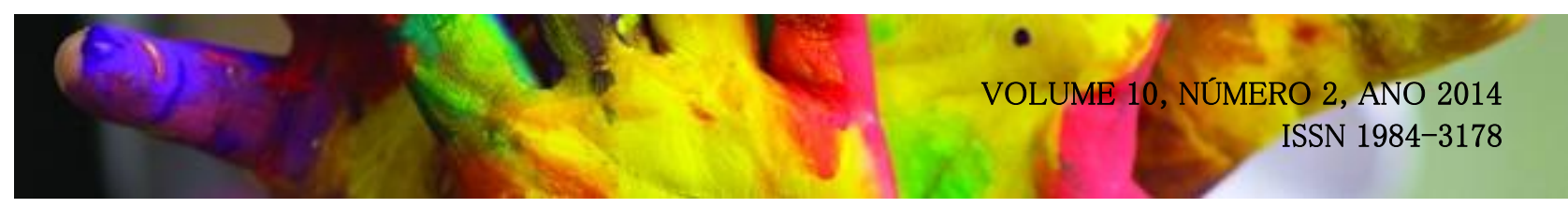

Em outras palavras, a partir de nosso estudo, temos compreendido que a avaliação não pode ser vista como a solução em si dos problemas enfrentados para fomentar o desenvolvimento e aprendizagem "satisfatórios" dos alunos, no entanto, quando aplicada adequadamente, torna-se uma possibilidade de revelar como ocorrem os processos de apropriação e construção de conceitos científicos pelos educandos, bem como contribui para o desenvolvimento de ações e práticas curriculares que favorecem a aprendizagem dos alunos com deficiência intelectual. Logo, podemos concluir que o estudo possibilitou o entrelaçar de fundamentados argumentos que evidenciaram não só instrumentos avaliativos adequados, como também ilustraram que a avaliação da aprendizagem é um processo longo e complexo. Todavia, capaz de contribuir significativamente para o desenvolvimento do elo existente na relação de ensino e aprendizagem entre docentes e alunos. O ato de avaliar revela mais do que o "aprendido até hoje", permite apreender o amanhã.

\section{REFERÊNCIAS}

BRASIL. Diretrizes nacionais para a Educação Especial na Educação Básica. MEC - SEESP, 2001.

Formação Continuada a Distância de Professores para o Atendimento Educacional Especializado - Deficiência Mental. SEESP/SEED/MEC, Brasília/DF - 2007.

- Política Nacional de Educação Especial na perspectiva da Educação Inclusiva. Brasília, janeiro de 2008.

Diretrizes Operacionais para o Atendimento Educacional Especializado na Educação Básica, modalidade Educação Especial. Resolução n 4. Brasília, 2009.

BRASIL. Nota técnica n 4. Brasília, 2014.

BRAUN, P. Uma intervenção colaborativa sobre os processos de ensino e aprendizagem do aluno com deficiência intelectual. 324f. Tese (Doutorado). Faculdade de Educação, Universidade do Estado do Rio de Janeiro, 2012.

GLAT, R. \& PLETSCH, M. D. Inclusão escolar de alunos com necessidades especiais. Rio de Janeiro: Eduerj, 2011.

PLETSCH, M. D.; GLAT, R. Plano educacional individualizado (PEI): um diálogo em práticas 


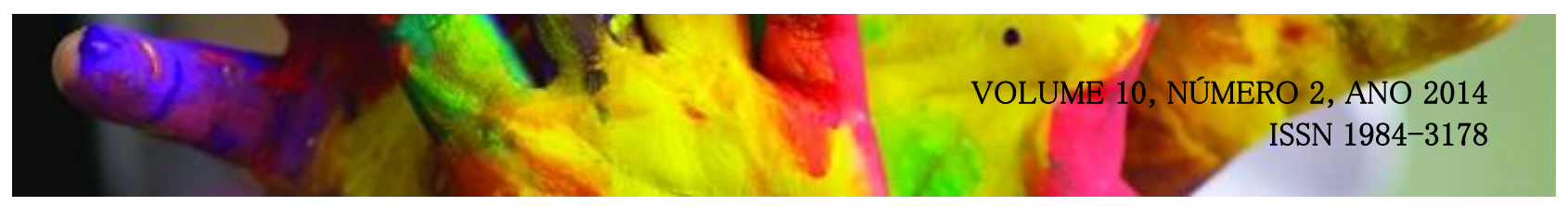

curriculares e processos de avaliação escolar. In: GLAT, R. \& PLETSCH, M. D. (orgs.). Estratégias educacionais diferenciadas para alunos com necessidades especiais. Rio de Janeiro: Eduerj, 2013, p. 17-32.

KASSAR, M. de C. Política de Especial na perspectiva inclusiva e o atendimento educacional especializado. In: MARTINS, L. de A. R.; PIRES, G. N. da L.; PIRES, J. (Organizadores.). Inclusão escolar e social: novos contextos, novos aportes. Editora da UFRN, Natal, 2012, p. 5567.

LURIA, R. A Pensamento e Linguagem: As últimas conferências de Luria. trad. [de] Diana Myrian Lichtenstein [e] Mário Corso; supervisão de trad. De Sergio Spritzer - Porto Alegre: Artes Médicas, 1986.251p.

MACHADO, R. S. Avaliação do potencial de aprendizagem de alunos com deficiência Intelectual. 2013. 150 f. Dissertação (Mestrado em Educação) - Universidade do Vale do Itajaí, Santa Catarina, 2013.

MENDES, G. M. L.; SILVA, F. de C. T.. Currículo e conhecimento escolar na contemporaneidade: desafios para a escolarização de sujeitos com deficiência. Arquivos Analíticos de Políticas Educativas, 22(79). Dossiê Educação Especial: diferenças, currículo e processos de ensino e aprendizagem. Editoras convidadas: Márcia Denise Pletsch \& Geovana Mendonça Lunardi Mendes. Disponível em: http://epaa.asu.edu/epaa/v22n80 . Acessado em agosto de 2014.

MIOTO, R. C. T. \& LIMA, T. C. S. de. Procedimentos metodológicos na construção do conhecimento científico: a pesquisa bibliográfica. In: Revista Katál, Florianópolis, v. 10, n. esp. p. 37-45, 2007.

PLETSCH, M. D. Educação Especial e inclusão escolar: uma radiografia do atendimento educacional especializado nas redes de ensino da Baixada Fluminense/RJ. In: Revista Ciências Humanas e Sociais, v. 34, p. 31-48, 2012.

\& OLIVEIRA. O Atendimento educacional especializado (AEE): análise da sua relação com o processo de inclusão escolar na área da deficiência intelectual. In: MILANEZ, S. G. C.; OLIVEIRA, A. A. S. de; MISQUIATTI, A. R. N. (Org.). Atendimento Educacional Especializado para alunos com deficiência intelectual e transtornos globais do desenvolvimento. São Paulo, Cultura acadêmica -Oficina uniersitária, p. 61-82, 2013.

Formação docente em tempos de inclusão escolar: em foco as práticas do atendimento educacional especializado. In: MARTINS, L. de A. R.; PIRES, G. N. da L.; PIRES, J. (org.). Caminhos para uma Educação Inclusiva - políticas, práticas e apoios especializados. Ideia, João Pessoa, p. 115-132, 2014.

Repensando a inclusão escolar: diretrizes políticas, práticas curriculares e deficiência intelectual. $2^{\mathrm{a}}$ edição. Rio de Janeiro: NAU, 2014a. 


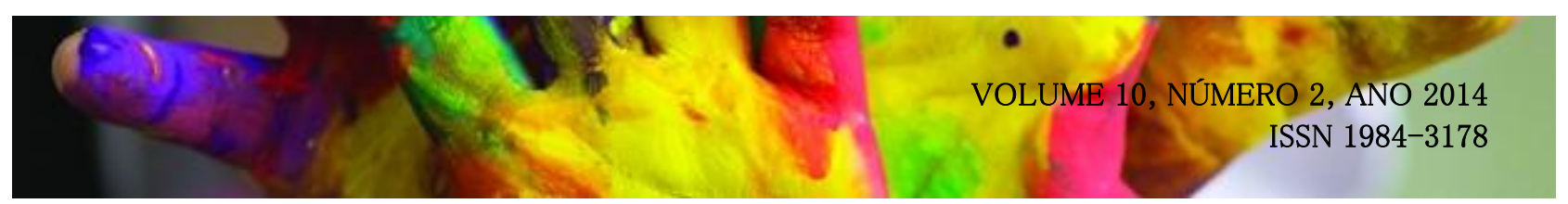

SOUZA, F. F. de. Políticas de educação inclusiva: análise das condições de desenvolvimento dos alunos com deficiência na instituição escolar. 213. 297p. Tese (Doutorado em Educação), Universidade Estadual de Campinas, Campinas/SP, 2013.

SCHUTZ, M. R. R. D. S. Avaliação escolar como instrumento de mediação da aprendizagem na educação inclusiva: desafios no cotidiano escolar. $140 \mathrm{f}$. Dissertação (Mestrado em Educação) Universidade do Vale do Itajaí, Santa Catarina, 2006.

TARTUCI, D. et al. Avaliação e o Atendimento Educacional Especializado. Poíesis Pedagógica, Catalão-GO, v.12, n.1, p. 67-93, jan/jun. 2014.

UNESCO. Declaração de Salamanca e linha de ação sobre necessidades educativas especiais. Brasília: CORDE, 1994.

VALENTIM, F. O. D. Inclusão de alunos com deficiência intelectual: considerações sobre avaliação da aprendizagem escolar. 2011. 143 f. Dissertação (Mestrado em Educação) Universidade Estadual Paulista, Marília, 2011.

\& OLIVEIRA. Avaliação da aprendizagem e deficiência intelectual na perspectiva de professores do ensino comum. Rev. Diálogo Educ., Curitiba, v. 13, n. 40, p. 851-871, set./dez. 2013.

VIGOTSKI, L. S. Obras escogidas V. Visor. Madrid, 1997. 